\title{
ENCONTRANDO IMAGENS NA E DA RUA DA PRAIA: RELATO DE UMA ETNOGRAFIA DE RUA
}

\author{
Patrícia Rodolpho \\ Cornelia Eckert e Ana Luiza Carvalho da Rocha (orientação)
}

"Pudesse eu contar, em três colunas, três quadras apenas da
Rua da Praia. Por certo nelas não caberia o turbilhão de vida e
de evocações grudado em suas calçadas".

(RUSCHEL; 1971:10)

Habitar uma cidade pode nos fazer acreditar que sabemos tudo sobre ela. Concretamente, vivenciamos o presente, com suas belezas, seus transtornos e as oportunidades que os lugares nos dão. O futuro é algo pelo qual uma cidade pode ser trabalhada: concepções de melhoria pelas quais se constroem e se destroem estruturas estéticas expressivos de cada época - edificações, ruas, avenidas, viadutos e túneis. Situação que, ao menos com relação às grandes metrópoles brasileiras, tende a ampliar-se e reestruturar-se.

Estes espaços são depositórios de uma memória da cidade. Uma memória que abarca um tempo muito maior que a existência pessoal porque conhece, por alguma perspectiva, a história dos lugares.

Esse conhecimento sobre lugares, mais distantes no tempo que a nossa própria memória, forma-se a partir das informações que recebemos em nossas vivências cotidianas como, por exemplo, os relatos daqueles que nos são próximos - parentes, vizinhos, conhecidos - e que nos situam nas suas trajetórias, nos contando "como eram as coisas no seu tempo".

Outras circunstâncias em que aprendemos sobre as cidades são, por exemplo, a escola, com sua história informal, e os veículos de comunicação de massa - rádio, jornais, revistas, TV, que nos colocam a par dos acontecimentos cotidianos que se referem a cidade. Um outro aspecto que vincula o indivíduo à sua cidade são as suas próprias trajetórias particulares, com suas peculiaridades - oportunidades de vida, projetos individuais, desejos, gostos, valores e a capacidade e interesse de cada um.

Todas estas formas de conhecimento vão, ao longo do tempo, construindo o imaginário dos habitantes de uma cidade. Imagens mentais que formam-se a partir de todas as informações acumuladas, mas que, entretanto, podem desconhecer aspectos reais ocorridos em tempos passados ou mesmo no presente. 
Assim, este trabalho propõe-se a analisar um dos espaços mais antigos e significativos de Porto Alegre: a rua dos Andradas, popularmente chamada de Rua da Praia. A opção por este espaço como universo de pesquisa, correspondeu às escolhas territoriais traçadas no âmbito dos objetivos do Projeto Integrado Cnpq das Professoras Cornelia Eckert e Ana Luiza Carvalho da Rocha, "Estudo antropológico de itinerários urbanos, memória coletiva e formas de sociabilidade no meio urbano contemporâneo" onde, na qualidade de bolsista de aperfeiçoamento CNPq em 1997 a 1998, pude entrar em contato com tais referências.

Estas referências decorreram de várias atividades desenvolvidas durante o Projeto Integrado: as entrevistas com informantes, as quais têm fornecido relato de pessoas que estão residindo há muito na Rua da Praia; do trabalho de pesquisa com o acervo das revistas "O Globo", cujos textos e imagens fornecem informações preciosas sobre o cotidiano da cidade; da pesquisa em imagens de Porto Alegre; bem como da busca pela formação teórica que contemple o aprendizado sobre a cidade.

Toda esta diversidade de informações impulsionou a realização da tarefa de Etnografia de Rua, que neste caso contempla o espaço da Rua da Praia, mais especificamente de três das suas quadras. Inicialmente, mapeia-se a rua em sua totalidade, mas a atividade etnográfica mostrou que cada quadra ou cruzamento de rua oferece uma infinidade de elementos e circunstâncias passíveis de serem exploradas pelo pesquisador.

Desta forma, iniciou-se a atividade etnográfica da Rua da Praia esquina com a Rua Senhor dos Passos. Este "final" é, na verdade, o ponto de ligação da rua e do centro com o restante da cidade. A partir daí, foram etnografadas três quadras onde se inicia o calçadão da Rua da Praia: a diferença entre os calçamentos foi determinante para o recorte espacial desta pesquisa, como será tratado mais adiante.

Esta etnografia foi elaborada a partir do método de pesquisa e da técnica de observação participante, mais precisamente através de uma etnografia de rua, segundo a definiram as orientadoras desta pesquisa Ana Luiza Carvalho da Rocha e Cornelia Eckert. O perambular e fotografar pela rua, foram acompanhados pela escrita de um diário de campo. A composição e recomposição do(s) cenário(s) da Rua da Praia a partir do trabalho de campo teve no recurso fotográfico, a estratégia de pesquisa fundamental.

No primeiro capítulo, procuramos contextualizar, através do tempo, o cenário e a ambiência da Rua da Praia a partir de seus elementos estéticos e das práticas comportamentais 
daqueles que a freqüentavam. Isto é construído com base em dados coletados em texto de antigos cronistas que viveram e experienciaram a cidade, nas entrevistas com informantes do Projeto Integrado, bem como informações buscadas em trabalhos científicos que abordam este tema.

O segundo e terceiro capítulos tratam especificamente da parte etnográfica: ao mesmo tempo em que o ambiente, suas características e circunstâncias são descritas, procura-se relacioná-lo ao passado, trazendo à tona seus resquícios, confrontando-os com o contexto atual do espaço. A renovação, a substituição e a sobreposição das formas estéticas da Rua da Praia são fatos contemplados em um ensaio fotográfico, apresentado ao final deste trabalho.

Não é o nosso interesse traçar a história da Rua da Praia, mas sim colocar as alterações pelas quais ela - assim como o centro de Porto Alegre - vêm passando. Mais do que isto procuramos com o recurso da imagem mostrar como elementos estéticos de tempos diferentes estão ali articulados.

Algumas questões nortearam nosso olhar:

Como ela apresenta-se esteticamente, quem a freqüenta e quais são as suas funções? Quais são as imagens que a Rua da Praia nos apresenta hoje e quais as suas relações com as imagens de outrora? Quais as imagens mentais recorrentes dos seus freqüentadores.

Trata-se de dar conta da memória dos que transitam entre a realidade atual e um forte sentimento afetivo relativo a tempos passados onde a prática do cotidiano nesta Rua era outra

Procura-se também colocar a situação de estar em campo realizando uma etnografia urbana, as peculiaridades e problemas que despertam a nossa atenção, nos instigando a conhecer mais a fundo cada aspecto ou acontecimento que apresenta-se aos nossos sentidos.

Assim, a Rua da Praia é tomada como um universo de análise quase infindável, seja porque a cada momento esbarramos com seus elementos históricos, que nos remetem a um tempo em que ela era realmente diferente do que é hoje, seja porque as práticas atuais dos usuários deste espaço também apresentam muitos elementos passíveis de análises mais atentas por parte do pesquisador.

A riqueza de significados da Rua da Praia, aliada à intensa atividade comercial e ao ininterrupto trânsito de pessoas, problematiza a atividade de campo, tornando este espaço por vezes adverso à observação, ao mesmo tempo que multiplica os focos de atenção para o observador. 


\title{
A Rua da Praia: vivências ao longo do tempo
}

Um dos aspectos que impulsiona a proposta de analisar a Rua da Praia, um dos espaços, mais tradicionais da Porto Alegre deriva, sem dúvida, do seu próprio tempo de existência enquanto via de passagem, local de comércio e residência de comerciantes, autoridades e família importantes: reconstituindo algumas das características deste espaço, tem-se aquele que já foi um de seus lugares mais aristocráticos. Monteiro nos ajuda na compreensão da importância da Rua da Praia para a cidade neste trecho:

\begin{abstract}
"A malha urbana, entendida como a rede de caminhos e lotes dentro das fortificações, estava constituída por três ruas que partindo da ponta da península atravessavam-na no sentido longitudinal e se encontravam diante do portão da vila. (...).

Essas ruas mudavam, de nome ao longo de seus percursos fazendo referências às peculiaridades do terreno ou a atividades importantes parar a comunidade. Assim ocorria com a rua da Graça e rua da Praia (atual Andradas), rua da Ponte e rua do Cotovelo (atual Riachuelo), rua da Igreja e Rua do Hospital (atual Duque de Caxias ). Estas foram as primeiras a receber calçamento, chafarizes para o abastecimento de água (1779), limpeza, policiamento e iluminação de candeeiro a óleo de peixe (1832). Nestas ruas residiam os comerciantes responsáveis pelo desenvolvimento do porto (...), as autoridades do governo da província e as famílias mais importantes e endinheiradas"
\end{abstract}

(MONTEIRO 1995:25).

No começo do século XIX, de acordo com as descrições de viajantes europeus, a Rua da Praia já era considerada a principal rua da cidade. Nessa época, esta era a rua mais próxima do Guaíba, razão pela qual ficou conhecida por este nome. Em 1820, Saint-Hilaire observava que ela era extremamente movimentada, foco do comércio da cidade: "Nela se encontram numerosas pessoas a pé e a cavalo, marinheiros, e muitos negros carregando fardos. É provida de lojas muito bem instaladas, de vendas bem sortidas, e de oficinas de várias profissões" (Saint-Hilaire, 1974:43). Segundo Dreys, comerciante inglês que residiu em Porto Alegre entre 1817 e 1825 , esta era a rua mais extensa e importante de Porto Alegre com respeito ao comércio e a população, sendo formada principalmente por casas altas "... de estilo elegante e moderna, quase todas habitadas por negociantes..." (Dreys, 1990:99 - 100). 
Esta rua era, portanto, habitada por ricos comerciantes, enquanto que as classes inferiores ocupavam "as ruas abertas sobre os planos superiores" (ibidem). Ainda na década seguinte (1833-1834), Isabelle além de notar a belezas das casas que ocupavam a Rua da Praia realçava sua função comercial, pois nela concentravam-se "todas as lojas e principais casas de comércio" (Isabelle, 1983:61)

Na segunda metade do século XIX, Porto Alegre passou por significativas transformações no seus aspectos urbanos: era a modernização e o início da feição burguesa da cidade, quando as praças e as ruas centrais de Porto Alegre perderam suas antigas formas e ganharam um novo perfil, sendo que a Rua da Praia era o eixo de efervescência urbana da época" (Pesavento, 1991:33; 1991b :37). Além disso, sempre foi um dos primeiros espaços da cidade a ser contemplado com as melhorias de serviços como iluminação, coleta de lixo e abastecimento de água.

A distinção de freqüentadores da Rua da Praia e a sociabilidade que praticavam é um aspecto bastante valorizado por cronistas da época. Segundo Achylles Porto Alegre, a livraria Americana foi a mais antiga do Estado, fundada em 1875 “...este antigo empório de livros tornouse, logo, o ponto convergente dos intelectuais, magistrados, advogados, estudantes, que não só iam ali comprar e encomendar livros, com trocar dois dedos de "sécca" leve e fugitiva (Porto Alegre, 1922:87). Outro dado interessante é que data de 1862 a primeira confeitaria da cidade, chamada "Confeitaria Schramm", localizada na Rua da Praia ( Mazeron, s.d.:91). Estas casa proliferam-se na virada do século, tornando-se talvez o principal ponto de encontro e reduto de sociabilidade.

Com o passar do tempo, a Rua da Praia continuou desenvolvendo fortemente seu comércio e intensificou o seu "glamour" que a caracterizou por muito tempo tornando-se "...um local de passagem, sem dúvida, mas também de encontro e de troca. É um espaço de prazer e uma vitrine imensa e viva, que se contrapõem aos objetos imóveis das vitrines das lojas" (Pesavento, 1992:64)

Nas obras de cronistas, é constante a alusão à qualidade e ao refinamento dos objetos comercializados na Rua da Praia. A valorização da existência de artigos importados, sobretudo da Europa, no comércio porto-alegrense parece dignificar a cidade e seus habitantes. Referindo-se especificamente à Casa Masson, Acchyles descreve os produtos lá encontrados: 
“...ostentando em suas vitrines custosas jóias, aparelhos a fantasia e outros objetos de arte, era nessa época, loja de roupas brancas para homens, e de perfumarias dos mais célebres fabricantes de Paris, Londres, Viena e Berlin.(...) Nunca vi coleção de chapéus de sol de seda, com cabo de marfim e madrepérola, bengalas de unicórnio, com castão de ouro, e da barbatana como ai "(Porto Alegre, 1922:22).

A leitura de Cronistas do Século XIX, como os escritos de Acchyles Porto Alegre por exemplo, possibilita a recomposição do cenário e da ambiência da Rua da Praia. Tais crônicas permitem que, durante o trabalho de campo etnográfico, o pesquisador detecte com mais atenção na atualidade uma série de elementos estéticos que permaneceram através dos tempos como, por exemplo, o estilo neoclássico da grande maioria dos prédios antigos que sobrevivem na Rua da Praia.

Outros cronistas mais recentes como Arquimedes Fortini e Nilo Ruschel continuam a descrever a Rua da Praia a partir de suas lembranças. O aspecto comportamental e os valores pelos quais os indivíduos eram considerados relacionavam-se também em função da vestimenta e dos lugares que freqüentavam, como os cafés que se tornavam redutos da sociabilidade masculina. Sobre a vestimenta Fortini coloca que: “... em Porto Alegre (...) sempre houve gente que gostou de trajar pelos últimos figurinos vindos do estrangeiro. $\mathrm{E}$ os pontos que costumavam freqüentar eram, naturalmente, aqueles mais centrais e movimentados da cidade, onde o melhor pudesse exibir seu "aplomb" e despertar a atenção alheia, notadamente do sexo feminino"(Fortini, 1953:32).

Até a Segunda Guerra Mundial a Rua da Praia estava recoberta das influências européias, onde os cafés e o footing da Rua da Praia eram a vitrina, onde os entretenimentos possibilitavam uma forma de exposição dos indivíduos, e onde o Centro de Porto Alegre era o lugar chique por excelência. Em seu trabalho sobre os cafés de Porto Alegre, Bernardo Lewgoy coloca a relação dos indivíduos com a zona central da cidade:

"Uma das funções mais importantes desempenhadas pelos cafés do Centro de Porto Alegre na primeira metade do século XX, era a de ser um dos pólos agenciadores de socialização secundária de indivíduos do sexo masculino de segmentos médios e superiores da cidade. (...) Nota-se também a representação acerca da permanência do hábito de passear pelo Centro, revelando o enraizamento da sociabilidade nesta região no plano da memória coletiva."

(LEWGOY; 1988:7) 
Entretanto, a Rua da Praia perdeu muito destas suas características glamourosas. Atualmente, como ocorre na maioria dos centros das grandes cidades brasileiras a Rua da Praia revela a descaracterização dos estilos arquitetônicos empreendidos e o comportamento primordialmente funcional de seus usuários. Ao invés do footting da Rua da Praia, prestigiado pelos moradores da cidade até a década de 50, observa-se hoje o movimento de uma população inteira, vinda de vários bairros com destino ao trabalho ou em busca de serviços diversos. A proliferação do comércio informal (camelôs, feirantes e músicos), os prédios antigos desgastados pelo tempo, em meio a outros estilos arquitetônicos bem mais funcionais, além das mudanças relativas ao estilo da indumentária para freqüentar este espaço são alguns dos aspectos estéticos importantes nos quais podemos detectar as transformações conseqüentes da passagem do tempo.

A corrente alteração que este espaço vem sofrendo é facilmente verificada quando contrapomos as crônicas ou fotografias antigas que nos contam sobre o comportamento, hábitos e indumentária refinados de seus usuários, a relatos atuais de entrevistados que ainda vivenciaram aquela ambiência. Com relação ao cotidiano e às lojas, uma antiga moradora da Rua da Praia nos conta:

“(...) muitas lojas foram descaracterizadas. Agora tu vê a casa Lyra. Era uma casa que há pouco tempo mantinha o mesmo estilo de quando ela era antiga. Agora ela é totalmente descaracterizada, não é mais a Lyra que a gente conheceu (...)

Tinha o Hermann, tinha umas lojas assim... e foram tudo fechando. O Bromberg... foram essas lojas que foram quebrando, o Bromberg era uma loja maravilhosa(...) Tu saía da matinê e ia passear na rua da praia, saía do cinema e ficavam as moças passeando e os rapazes iam pros cafés. Era uma beleza essa Rua da Praia.”

Outra antiga moradora do Centro de Porto Alegre relata a sua primeira impressão da Rua da Praia, ao vir residir em Porto Alegre em 1953. Narra ainda as formas como era aproveitada a rua em termos de distração, deixando claro em sua narrativa a alteração da sua própria conduta diária relativa ao uso deste espaço: 
Há muitos depoimentos significativos de pessoas que freqüentaram com regularidade a Rua da Praia em outras épocas, contextualizando com precisão as alterações que vem ocorrendo neste espaço. Entretanto, quando procuramos saber da relação de pessoas mais jovens com a rua, entramos em contato com relatos que falam da dificuldade de se transitar pela zona central ou, inclusive, de sua certa aversão ao Centro e à Rua da Praia. Atualmente, para muitas pessoas é preferível excluir estes lugares de seus percursos cotidianos, denotando a redução de um sentimento afetivo que este espaço tradicionalmente despertava.

Ao contrário dos informantes que geralmente estão por volta dos 50 anos, uma informante de 18 anos, residente em um bairro de classe-média alta de Porto Alegre - afastado do Centro -, não demonstra nenhum entusiasmo em falar sobre a Rua da Praia:

“(...) Ah! Eu não gosto de ir no centro, não gosto mesmo, até porque é muita gente, eu me perco, me sinto totalmente perdida no Centro, não me acho muito bem lá. Eu até tenho medo de ir no centro, de assalto(...)"

E continua, relatando as suas poucas experiências no Centro da cidade:

“(...) Eu fui fazer um passeio com a faculdade, lá no centro, sobre arquitetura. Foi bom porque eu fiquei sabendo de um monte de prédio que estão ali há um tempão. Eu vou lá quando preciso comprar material na Casa do Desenho, e só. Ou se eu preciso ir na Mesbla, alguma coisa assim que não tenha por aqui. Ou quando eu vou na Biblioteca Pública(...)"

O imaginário dos habitantes da cidade de Porto Alegre acerca daquela que outrora foi a sua principal e mais aristocrática rua se altera, assim como a própria Rua da Praia foi se alterando ao longo do tempo. Passando por destruições e construções, processos de renovação, ela é hoje uma ambiência popular. Os artigos refinados são, atualmente, encontrados nos shopping-centers, ou outros pontos da cidade, cedendo lugar aos objetos vendidos pelos inúmeros vendedores ambulantes. A sociabilidade, na figura dos homens de mais idade conserva alguns traços de épocas anteriores, mas a Rua da Praia não é mais um lugar de sociabilidade de entretenimento por excelência.

Guardando resquícios, ela revela-se aos olhos de quem a observa com mais atenção. E assim, passamos a esta atividade: observar a Rua da Praia, descrevê-la e, com certeza, admirá-la em suas inúmeras facetas. 


\section{Trajetos e Cruzamentos}

A etnografia da Rua da Praia exigiu que, ao longo do trabalho de campo, fossem sendo desenvolvidos técnicas e instrumentos de observação que permitissem uma melhor e mais clara abordagem deste espaço. Em outras palavras, todas as decisões tomadas deram-se em função das dificuldades que se apresentavam e buscavam facilitar e otimizar a busca pelos dados.

A primeira e principal decisão tomada foi a de diferenciar na rua os espaços de trajetos e cruzamentos e, em cada um destes, foi adotada uma metodologia para que se pudesse compreendê-los melhor. De fato, os resultados encontrados nestes lugares demonstraram algumas diferenças que podem ser atribuídas a sua própria conformação espacial.

Enquanto nos trajetos houve, involuntariamente, uma análise mais voltada aos aspectos físicos e materiais, nos cruzamentos de rua foi possibilitada a observação de circunstâncias envolvendo os indivíduos que ocupam a Rua da Praia.

Portanto, iniciaremos a descrição pelos trajetos da Rua da Praia, procurando sistematizar a forma pela qual estes espaços foram abordados, seus problemas e suas descobertas e, posteriormente, faremos o mesmo com os cruzamentos de rua.

\section{Análise de trajetos}

\section{Circulando pela "Subida da Rua da Praia"}

Há, possivelmente, alguma singularidade em etnografar um objeto de pesquisa já conhecido de antemão. Coloca-se esta questão porque, ao realizar a etnografia urbana em uma cidade ou espaço já conhecidos, é natural que o pesquisador esteja imbuído de uma série de préconceitos com os quais ele provavelmente entrará em choque durante o trabalho de campo. Neste momento, há uma necessidade de mudança de olhar com relação ao objeto pesquisado e este pode ser o primeiro problema da atividade de campo.

No caso de uma etnografia urbana, essa mudança de olhar implica a observação atenta de elementos que podem ser conhecidos de antemão, mas que até então não eram percebidos isoladamente, fazendo parte indivisível da imagem da ambiência do lugar. E a primeira imagem de uma ambiência como a da Rua da Praia mostra-se confusa, forte e movimentada, revelando e

escondendo elementos a partir da própria percepção do pesquisador. $\mathrm{O}$ que, afinal, deve ser etnografado para suprir o recorte do objeto de pesquisa? 
Na confusão de elementos estéticos que ocorre na Rua da Praia é preciso que o pesquisador reordene-os, obrigando-se a selecionar aqueles que constituam-se mais pertinentes para o trabalho. Neste caso, procurou-se por aqueles elementos que deixassem transparecer as alterações da atmosfera do local e que revelassem a substituição, renovação ou sobreposição das formas estéticas da Rua da Praia.

Para isso, a intenção inicial no trabalho de campo foi a de observar apenas os prédios e estabelecimentos comerciais, para que a necessidade de ordenação do espaço fosse suprida. A observação centrou-se nos estilos arquitetônicos, em busca das edificações mais antigas, bem como de suas funções atuais. Contudo, havia ainda o objetivo de observar a dinâmica da Rua da Praia com relação ao aspecto humano. Como veremos mais adiante, esta foi uma das dificuldades sentidas durante a etnografia dos trajetos e a observação de tais aspectos ocorreu somente quando o trabalho de campo direcionou-se para os cruzamentos de rua.

Também pretendia-se perceber qual era a situação real da Rua da Praia com relação à higiene e conservação do espaço físico: conservação das calçadas, dos prédios, do sistema de iluminação.

Outros aspectos micro como cartazes, latas de lixo e a própria colocação dos esquemas publicitários (sendo que de forma alguma a questão da publicidade na Rua da Praia pode ser considerada um aspecto micro) foram encontrados durante o trabalho de campo e revelaram-se bastante significativos.

Metodologicamente, optou-se caminhar circularmente pela "Subida da Rua da Praia". Caminhou-se por uma das calçadas, olhando e anotando em sequiência cada prédio do lado oposto com suas características: antigo ou novo, restaurado ou não e em que condições, tipos de ornamentos e qual o tipo de comércio que abriga. Posteriormente, para facilitar a visualização dos prédios foi criada uma Ficha de Reconhecimento de Edificações. Apesar de considerar todas as edificações, inclusive pela necessidade de delimitar o espaço que cada uma ocupa, o foco de atenção continuou centrando-se nos prédios mais antigos. São estes que conformam uma das faces que contrastam os efeitos da passagem do tempo na Rua da Praia.

Neste trajeto, foram encontrados geralmente sobrados de uso misto, que datam da virada do século, principalmente do início do século XX, em função de características estéticas referentes às suas fachadas. Com relação à estética arquitetônica, a predominância está no estilo colonial adaptado ao difundido estilo neoclássico, e no posterior ecletismo a ele associado, que possibilita uma conciliação entre as inovações tecnológicas que eram constantemente assimiladas 
(REIS FILHO: 136,169).

Provavelmente a casa mais antiga encontrada nas três quadras etnografadas é uma que está situada na Subida da Rua da Praia, a qual já foi denominada casa com porão alto, representando a transição entre os velhos sobrados e as casas térreas (REIS FILHO: 34)

Esta edificação traz alguns traços da arquitetura do final do século XIX, como por exemplo: vergas das aberturas retilíneas ou em arco pleno com bandeiras de ferro, calha, platibanda simples e cimalhas salientes para remates. Na pesquisa em imagens, esta casa foi encontrada em uma fotografia que data do final do século passado. Atualmente está restaurada abrigando uma loja de artigos femininos.

Em conjunto com esta casa, estão outras três edificações, duas delas sobrados de uso misto (comércio no térreo e habitação na parte superior), cujas características estéticas nos reportam ao final do século passado: grades e peitoris de ferro, vergas das aberturas retilíneas, platibandas com balautrada e/ou vasos de louça, cimalhas.

A terceira edificação do conjunto, cujos elementos estéticos do início do século torna-a diferente das outras em função de fachadas curvas, frontões e ornatos, balcão de barro, colunas e pilastras, bem como cimalha de diversas formas.

Neste trajeto há duas edificações que são interessantes em função do comércio que desenvolvem: uma delas abriga uma das filiais de rede de lojas Butikão, que é uma empresa que sempre primou pela sofisticação, pelo atendimento diferenciado e pelo preços altos. Na verdade, até alguns anos atrás ainda eram encontradas muitas lojas chiques na Rua da Praia, mas o Butikão é um dos resquícios deste fato. Atualmente, no trajeto da "Subida", encontra-se muitas lojas de 1,99, magazines populares e lanchonetes, bem como cerca de 4 ou 5 óticas.

Chegando ao fim da calçada, ao pé da lombinha está um dos prédios em melhor estado de conservação devido, provavelmente, as restaurações que vêm recuperando-o ao longo do tempo. O estilo neoclássico, com fachadas curvas, frontões e ornatos, cimalhas diversas, colunas e pilastras está emoldurado pela estética Mc’Donalds. A filial da lanchonete neste aí localizada há alguns meses explica o fato de esta esquina estar mais tumultuada, pois tem-se acesso à loja pelas duas ruas - Andradas e Dr. Flores - , enfileiram-se a frente do prédio para examinar o painel que divulga os lanches, ao mesmo tempo que alguns funcionários distribuem volantes publicitários ao fluxo contínuo de pessoas. 
Também foram encontrados edifícios que provavelmente são fruto do impulso de modernização ocorrido em Porto Alegre: arranha céus construídos em Porto Alegre, como o Edifício Egas Moniz, fazem parte da época na qual os casarões cederam lugar aos prédios e a verticalização do Centro.

Outro aspecto que devemos ressaltar na análise estética da Rua da Praia é a utilização das placas publicitárias, inclusive por estarmos em um aclive que nos permite visualisá-las melhor. E indo mais além, é necessário atentarmos para a forma como estas placas publicitárias são utilizadas. Podemos observar que estão em grande quantidade, em formatos grandes e que, sobretudo, em cada uma delas há um apelo de consumo que se pretende diferenciado, seja pelas cores, pelo design ou pelo material utilizado.

Considerando que estas placas publicitárias estão acopladas nos prédios, a publicidade torna-se um estímulo visual que acaba quase por suplantá-los. A adição de uma - em alguns casos mais de uma - placa publicitária a uma edificação altera sua estética. E esta prática em grande escala, como vem ocorrendo no caso da Rua da Praia, tem certamente alterado toda a ambiência do lugar.

Deve-se levar em conta ainda que as alterações relativas aos pontos comerciais inaugurações e fechamentos - levam e trazem não só as placas publicitárias, mas também transformam a ambiência da cada estabelecimento. Por ,exemplo, se uma loja de roupas femininas, com uma decoração um pouco mais sofisticada é fechada, e neste ponto é inaugurado um estabelecimento que comercializa produtos de 1,99 - circunstância que ocorreu recentemente na Subida da Rua da Praia - obviamente haverá uma série de alterações e substituições decorrentes deste fato. Isto não se dá apenas no âmbito dos aspectos materiais que aqui estão sendo analisados, mas também geram reflexos nas expectativas daqueles que têm na Rua da Praia um do seus locais de passagem e de consumo.

Como foi referido anteriormente, apesar de centrar a análise nos prédios e pontos centrais a observação de outros elementos também foi contemplada. O estado de conservação do aspecto físico está caracterizado pelas rachaduras dos prédios, pelos vidros quebrados, sujos ou trincados, pelos madeirames que apresentam fissuras. Há muita sujeira na Rua da Praia, há uma grande quantidade de fios elétricos que percorrem cada espaço da fachada dos prédios, como uma continuação emaranhada, que vai aos poucos parecendo-se com uma rede que junta todos prédios. O sistema de iluminação da Rua da Praia, que mescla aos postes de luz corriqueiros os antigos lampiões - cerca de 2 por calçada - , é outro dos resquícios da Porto Alegre antiga. 
Assim, a multiplicidade de estímulos visuais que estes elementos estéticos transmitem conformam a ambiência da Subida da Rua da Praia, a mistura do antigo com o novo ocasionada pela necessidade de substituição das formas que o próprio tempo exige.

\section{Observação em um terreno plano: a Rua da Praia compreendida entre a Dr.Flores e a}

\section{Vigário José Inácio}

A Rua da Praia tem como uma das suas principais características o fato de que, ao longo de seu percurso, é permitida ou não a livre circulação de veículos. Na Subida da Rua da Praia, por exemplo, esta circulação não só é permitida, como é bastante intensa em função do fluxo proveniente da Rua Dr. Flores - além de um tradicional ponto de taxis localizado neste local, várias linhas de lotações que partem do Centro de Porto Alegre utilizam a Dr. Flores e a Subida da Rua da Praia como ligação com os bairros.

Já a quadra seguinte que passamos a analisar, compreendida entre as ruas Dr. Flores e Vigário José Inácio, é a primeira onde o livre trânsito de veículos não é permitido, voltando a ocorrer somente a partir da Rua Caldas Júnior, cinco quadras abaixo. Provavelmente esta seja uma das diferenças significativas que alteram a utilização do espaço entre estas duas quadras, e uma das conseqüências estéticas da não circulação de veículos está na permanência do calçamento de paralelepípedos da Rua da Praia. Nilo Ruschel, em seu livro de lembranças "Rua da Praia" mencionava-o em muitos momentos:

"Uma rua não tem data e, queira Deus, não se lembre de levantar polêmica em torno da fundação da Rua da Praia. (...) Ao invés de rugas, ela apresenta lisa e sempre bela a pavimentação. Suas pedras, formando um belo desenho, que tem chamado a atenção dos visitantes, receberam a passagem de milhões de passos. (...) E porque devemos respeitar-lhe a imagem, tomara que não levem adiante uma idéia que alguém sugeriu, de reformular o chão da Rua da Praia: arrancar tudo e substituir o que está por uma chapa lisa e nivelada, de asfalto ou concreto" (RUSCHEL: 1971:55-56)

Escorregadio esburacado, desgastado pelo tempo com seus desenhos originais alterados em função de prováveis "reformas", este antigo calçamento certamente é responsável por uma grande quantidade de tombos que diariamente sofrem os passantes da Rua da Praia. Esse caráter poético que refere-se à antigüidade e ao desgaste do calçamento poderá, em algum momento, tornar-se argumento para o seu desaparecimento em favor de alguma alternativa mais moderna e funcional. Assim, a obtenção de registros de elementos estéticos históricos, que muitas vezes não 
são devidamente valorizados e que podem ter seu prazo de existência finado. Torna-se fundamental e urgente.

Nesta quadra da Rua da Praia continuam presentes os lampiões e os prédios antigos, em meio à infindável quantidade de placas publicitárias das lojas. Aqui , encontramos um exemplo bastante significativo e que ilustra com muita clareza a renovação e a sobreposição de formas na Rua da Praia. Trata-se de um Sobrado do início do século que abriga uma loja de calçados, cujo fachada que contém as logomarcas dos produtos que a loja comercializa. Apenas a borda do prédio pode ser visualizada, se observada com atenção. Nela, vemos a platibanda com frontões e ornatos, cimalhas, adornos em gesso e figuras esculpidas.

Um suporte de aço reveste o restante do prédio, onde além do nome da empresa foram colocadas diversas logomarcas de calçados: novamente encontramos com intensidade a multiplicidade de formas que os designs das logomarcas apresentam, mas que perdem a sua força individual quando apresentados em conjunto, como neste caso. A publicidade na Rua da Praia caracteriza-se por ser um estímulo visual que suplanta os prédios, cria uma tensão entre a força das cores que utiliza e os tons cinzentos constantes das edificações.

O exemplo desta loja de calçados revela algo corriqueiro em espaços comerciais antigos: a passagem do tempo mostra-se visualmente. Este aspecto temporal-visual ocorre a partir da articulação de elementos estéticos diferentes, que são diferentes porque foram concebidos em épocas diversas, a partir das tecnologias que estas épocas proporcionam ou proporcionavam. É, sem dúvida, o caráter tecnológico que origina essa multiplicidade de elementos visuais, que vão tomando seu lugar no espaço das cidades e que, por outra razão, sobrevivem ou não ao tempo que passa.

Dois outros Sobrados que consideramos relevantes são os que atualmente abrigam as lojas Tabajara e Gaston. O primeiro tem a influência positivista registradas em suas cimalhas, além da platibanda e as vidraças. O segundo, provavelmente um pouco anterior, tem adornos mais rebuscados, balcão no mesmo material do prédio, além de uma grande placa publicitária.

\section{Breve espaço de continuidade: a Rua da Praia entre a Vigário José Inácio e a Mal.Floriano Peixoto}

O trajeto da Rua da Praia compreendido entre as ruas Vigário José Inácio e Mal. Floriano é tomado aqui enquanto um espaço de continuidade por guardar algumas das mesmas 
características da quadra anterior, quando se pretende uma análise em função dos elementos estéticos que configuram uma determinada anbiência.

As três descritas neste trabalho, e em particular as duas últimas, foram analisadas enquanto um conjunto singular em função das características estéticas que conformam a sua ambiência. Tal ambiência é o resultado de constantes transformações - no caso da Rua da Praia pode-se colocar estas transformações enquanto conseqüências de tentativas de renovação - de um espaço, a partir da presença de certos elementos estéticos.

Os lampiões e o calçamento, por exemplo, são alguns dos elementos estéticos que, a partir de características de funcionalidade e/ou utilidade específicas, podem tornar claras muitas concepções acerca do mundo como os indivíduos vivem o cotidiano. A questão dos desenhos dos calçamentos nos leva a perceber uma sociedade em que, possivelmente, o hábito de andar, caminhar, desfilar, estava imbuído de sentimentos mais contemplativos.

Os desenhos elaborados, não só na Rua da Praia, mas em outros calçamentos da cidade, não eram projetados para não serem apreciados. Entretanto, na Rua da Praia o calçamento não é percebido pelos seus usuários porque o ato contemplativo não tem vez. Trata-se de um espaço onde há muitos estímulos aos sentidos, principalmente visuais e sonoros. A todo o momento surgem acontecimentos que chamam e exigem a atenção direta. Assim, pode-se acreditar que o sentimentos de uma época está em harmonia com as formas desta época.

Os antigos postes de iluminação pública, ou os chamados lampiões, são outro resquício de tempos anteriores. Muitos já foram retirados, e durante a etnografia destas três quadras foram contados dois lampiões por calçada. À noite, fornecem uma esplêndida iluminação que, infelizmente, os porto-alegrenses via de regra não conhecem. Afinal, a Rua da Praia não é mais um lugar de passeio por excelência.

Assim, até este ponto nos detivemos observando espaços da Rua da Praia que caracterizam-se fisicamente por constituírem-se em trajetos. A análise de um trajeto, estrutura composta de dois sentidos de movimento, implica um tipo de observação que coloca o próprio pesquisador em movimento. Ao observar a Rua da Praia ao longo destas três quadras, embora em vários momentos a parada em algum ponto tenha sido de fundamental importância e nelas efetivamente ocorreram as anotações para a escrita do diário de campo, o caminhar pela rua permaneceu enquanto atividade primordial para a coleta de dados. 
Ir e voltar no trajeto, procurando manter os pontos de observação naqueles aspectos invisíveis, constitui em uma tentativa no sentido de aprender aquilo que não se vê, mas que se sente na Rua da Praia.

Provavelmente, deve-se ao fato de caminhar por um trajeto procurando observar o quê está meio escondido na Rua da Praia, que acertou uma análise bem mais direcionada à estética dos aspectos físicos deste espaço. Prédios, função dos pontos comerciais, sistemas de iluminação, utilização e conservação do espaço físico foram, involuntariamente, privilegiados perante os usuários da Rua da Praia.

Passaremos agora a relatar a atividade de campo nos cruzamentos de rua, onde ocorreu a observação dos indivíduos que transitam e trabalham e, porque não dizer, passeiam na Rua da Praia.

\section{Análise de cruzamentos de rua}

O início das observações da Rua da Praia certamente foi pela alteração na conduta de observação causada pele própria alteração do espaço físico. Ora, enquanto nos espaços de trajeto que foram analisados até agora, havia uma preponderância na movimentação em dois sentidos ir e vir- , nos cruzamentos - também denominados enclaves - ocorre uma multiplicação destes sentidos, influenciando no fluxo do movimento.

Os cruzamentos mostram-se muito mais fervilhantes do que os trajetos, multiplicaram-se os acontecimentos: o sentimento de que na Rua da Praia "todo o mundo está passando o tempo todo" foi atenuado. Pôde-se observar as pessoas que param, que conversam, que trabalham. Aqui, estamos considerando isto um fato, mas pode ser uma decorrência da metodologia utilizada no trabalho de campo.

Enquanto nos trajetos o caminhar era propício à atividade de campo, nos cruzamentos permanecer em um ponto durante um tempo prolongado tornou-se fundamental. Ora, um cruzamento é composto, via de regra, por quatro esquinas. A riqueza da etnografia dos cruzamentos pode ser intensificada se o pesquisador observar o espaço a partir destes quatro ângulos, alterando o seu ponto de vista. 
Assim a metodologia utilizada na etnografia dos cruzamentos partiu da permanência em cada uma das esquinas do cruzamento, afim de contemplar estes espaços na sua totalidade para compreendê-los melhor. Outro recurso que auxiliou na contextualização destes espaços foi a criação e utilização de fichas para reconhecimento dos cruzamentos.

Além disso, os cruzamentos de rua revelaram-se muitos diferentes uns dos outros. Em cada um ocorrem circunstâncias específicas e particulares, devendo ser percebidos com suas singularidades. O primeiro cruzamento com o qual se depara a descer a "Subida da Rua da Praia" é o da esquina com a Dr. Flores.

\section{O cruzamento da Rua d Praia com a Dr. Flores}

Neste primeiro cruzamento foram experienciadas as possíveis abordagens na observação de um local em função da mudança de ponto de vista pelo observador. Em um primeiro momento, permaneceu-se ao lado do Mc'Donalds e logo percebeu-se um dos seguranças da loja enxotando um menino de rua. Tais seguranças têm, principalmente, a função de dispersar as crianças que podem vir a pedir "uns trocados" no guichê que fica situado em, frente à calçada.

Nas esquinas, o comércio formal conta com as lojas do Mc'Donalds, Aduana (loja de vestimenta masculina), Bella Modas (tradicional loja de vestimentas femininas, cujos preços freqüentemente são altos), e uma agência bancária. O comércio informal está na atividade dos sorveteiros, pipoqueiros e camêlos, além dos carregadores que transitam pela Rua da Praia para levar mercadorias em seus carrinhos. Também é este um dos pontos onde seguidamente os policiais da Brigada Militar postam-se.

Além disso, há um antigo ponto de taxi nesta esquina, cuja a fila é sempre imensa e adentra a Rua De. Flores afora. Com o trânsito de veículos permitido, há o escoamento uma grande quantidade de veículos, sobretudo de várias linhas de taxis-lotações em direção à Avenida Independência, que distribui o trânsito para outras partes da cidade. A Dr. Flores é uma rua tumultuada, que tornou-se muito estreita para se dividir seu espaço entre transeuntes e veículos.

Desta forma, foi nos cruzamentos de rua que percebeu-se a intensidade do trabalho na Rua da Praia. Há uma aglomeração de gente que está atuando todo o tempo em função do trabalho, especialmente em função do comércio informal. 
As pessoas que param esperando alguém, os grupos de homens que conversam, as pessoas que vêm ao Centro juntas para realizar suas tarefas se despedindo e indo cada uma para seu rumo, assim as paqueras entre os alunos de cursinhos pré-vestibulares próximos foram vistas durante a permanência neste cruzamento de rua.

A impressão de rapidez constante se desfaz ao nos depararmos com uma sociabilidade que está implícita à dinâmica da Rua da Praia.

\section{O cruzamento da Rua da Praia com a Vigário José Inácio}

O cruzamento da Vigário com a Rua da Praia é, mais do que o anterior, explorado pelos vendedores ambulantes e trabalhadores informais. Certamente em função do que, com a aus6encia de veículos eles podem colocar ou circular em um espaço bem mais amplo.

Aqui, em uma das esquinas das lojas Marisa (rede nacional de lojas voltadas ao público feminino), com sua vitrina padrão que permite, através das paredes envidraçadas, a visualização dos manequins. Nas outras esquinas, há uma loja de calçados e um aloja de artigos direcionados ao público jovem. Interessa-nos aqui salientar a beleza dos prédios que situam-se nestas esquinas. Provavelmente são os primeiros arranha-céus construídos na região central de Porto Alegre.

$\mathrm{Na}$ quarta esquina situa-se a loja Kirk, com a sua marca aristocrática - a coroa registrada na logomarca, é tradicional na comercialização de artigos masculinos. Este é um bom exemplo de transformações do caráter comercial na Rua da Praia: o comércio que sempre se distinguiu pelas qualidades e elegância de seus artigos é agora suplantado por uma infinidade de barraquinhas de comércio de rua nada sofisticado.

Neste cruzamento os diferentes tipos de trabalho informal são desenvolvidos: há aqueles trabalhadores quer possuem uma barraquinha com licença da Prefeitura Municipal, há os camelôs que depositam suas mercadorias sobre caixotes de madeira ou papelão, há os que distribuem os volantes de propaganda (divulgação de cortes de cabelo, compara/venda de ouro, cursos, fotografias 3x4), vendedores de loteria, de algodão-doce e maça do amor. Ou mesmo qualquer pessoa vendendo qualquer objeto.

Reflexo de um país onde o desemprego faz parte da vida da população, o comércio é a forma que a grande maioria tem de "se defender", e tem um lugar significativo nos espaços centrais das grandes metrópoles brasileiras. A conseqüência disto é que, no Centro de Porto 
Alegre tem havido uma intensa repressão aos ambulantes que trabalham com circulação de produtos sem tributar impostos. A ação dos fiscais da Prefeitura Municipal tem sido intensa, e a participação da Brigada Militar ocasionou alguns conflitos de caráter mais violento.

Ainda com relação aos trabalhadores informais, especificamente os ambulantes, é normal que se tenha a impressão que "eles não tem um lugar fixo" e, inclusive, que em um mesmo local eles não são sempre os mesmos.

Entretanto, a experiência neste cruzamento mostrou que os ambulantes determinam um lugar para suas atividades - se foi contatado um informante em um espaço qualquer da rua, o pesquisador terá a possibilidade quase certa de encontrá-lo novamente no mesmo lugar por muito tempo. Isto foi percebido não só na Rua da Praia, mas em outros pontos do Centro da Cidade.

No caso deste espaço, os trabalhadores geralmente posicionam-se no mesmo espaço dentro do enclave. A marcação do espaço é um traço do desenvolvimento do trabalho informa: o harpista não toca em qualquer esquina do cruzamento, assim como o vendedor de maçãs-do-amor resguarda o seu posto na sua esquina.

A divisão do espaço sonoro também foi sentida em algumas incursões a campo: aqueles que anunciam verbalmente os seus produtos não o fazem ao mesmo tempo e a divulgação e a divagação mais ou menos sistematizada.

Estas considerações sobre a dinâmica destes espaços não pretendem fixar conceitos, mas fornecer pistas para que, a partir das quais, possam ser formulados outros estudos que privilegiem a utilização dos espaços urbanos por aqueles que o utilizem.

\section{Conclusão}

Este estudo, tendo como objetivo de pesquisa a Rua da Praia, um dos marcos referenciais da cidade de Porto Alegre, objetivou analisá-la a partir de suas feições estéticas, impressões de seus freqüentadores, cronistas do passado e, sobretudo, a partir de uma atividade etnográfica.

As modificações pelas quais este espaço têm passado ao longo do tempo dos anos, têm determinado o seu cotidiano. De uma rua aristocrática e fundamental para a atividade comercial da cidade, apesar de sua pluralidade de sociabilidades, ela transformou-se em lugar de vivências basicamente populares. De um ambiente de entretenimento e glamour, atualmente o dia-a-dia da Rua da Praia é basicamente funcional, onde o trabalho sob diversas circunstâncias tornou-se o foco principal e motivador de seu intenso movimento. 
A atividade etnográfica, aliada à utilização do recurso fotográfico, permitiu que fossem detectadas as renovações, substituições e sobreposições das formas presentes neste espaço. As narrativas de informantes, bem como os escritos de antigos viajantes e de cronistas do passado, auxiliaram na reconstrução deste ambiente e, consequentemente, na contraposição entre os diferentes tempos que foram vivenciados nesta que é uma das primeiras vias metropolitanas de Porto Alegre.

A descaracterização do perímetro central acarretou, de certa forma, a sua desvalorização pelos habitantes da cidade. Atualmente, o imaginário construído por uma parcela significativa da população acerca da Rua da Praia tende a desvalorizá-la. O cotidiano que aí se desenrola não mostra-se atrativo aos atuais padrões de bem-viver das sociedades urbanas. Fatores como segurança, limpeza e, até mesmo a possibilidade de estacionamentos, além da ambientação pouco atrativa, têm afastado os moradores da cidade.

Este estudo procurou trazer à tona uma série de aspectos que são características dos cenários dos centros urbanos das grandes metrópoles brasileiras. Os contrastes processos de renovação que ocorrem de tempos em tempos têm, com certeza, o intuito de dar continuidade a uma espécie de vivência destes espaços em concordância com os padrões e valores vigentes em cada época. A dinâmica da Rua da Praia é, a partir destas considerações, uma rica fonte para pesquisa frutíferas no âmbito da Antropologia Social. 


\section{Referencias:}

DREYS, Nicolau. 1990 Notícia descritiva da Província do Rio Grande de São Pedro do Sul. Porto Alegre, Nova dimensão/EDIPUCRS.

FORTINI, Archymedes. 1953 Revivendo o passado. Porto Alegre. Livraria Sulina. ISABELLE, Arséne. 1983 Viagem ao Rio Grande do Sul (1833-1834). Porto Alegre, Martins Livreiro.

MONTEIRO, Charles. 1995 Porto Alegre - Urbanização e Modernidade. Porto Alegre, EDIPUCRS.

PESAVENTO, Sandra Jatahy. 1988 De escravo a liberto: um difícil caminho. Porto Alegre, Instituto Estadual do Livro.

PESAVENTO, Sandra Jatahy 1991 Memória Porto Alegre: espaços e vivências. Porto Alegre, Ed da Universidade/UFRGS - PMPA.

PESAVENTO, Sandra Jatahy 1992 O Espetáculo da Rua. Porto Alegre. Editora da Universidade/UFRGS.

PORTO ALEGRE, Achyles 1922 Noutros Tempos. Porto Alegre, Livraria do Globo. RUSCHEL, Nilo 1971 Rua da Praia. Porto Alegre, PMPA.

SAINT-HILAIRE, Auguste de. 1974 Viagem ao Rio Grande do Sul. São Paulo, Editora da Universidade de São Paulo/Itatiaia. 